\title{
Minimal thickness of cut layer in the vicinity of the cutting edge rounding
}

\author{
Minimalna grubość warstwy skrawanej \\ w obszarze zaokrąglenia krawędzi skrawającej
}

\section{BORYS STORCH \\ ANNA ZAWADA-TOMKIEWICZ ŁUKASZ ŻURAWSKI *}

The article presents an evaluation of the results of experimental tests useful for determining the minimum thickness of cut during machining of single-point tools of defined geometry. After completing the tests for several cut materials and types of tool materials, extrapolation equations were developed while maintaining constant temperature. Factors interfering with the mechanism of separation, influencing the measurements of the components of the cutting force and the cutting temperature depend on the cut material and the material of the tool.

KEYWORDS: cutting force, temperature, free orthogonal cutting, cutting edge rounding

Due to the very dynamic course of the separation of the machined material when replacing the allowance in the chip, it is easy to observe the existence of limited thickness of the machined layer. Closing in of the cutting edge on the workpiece is accompanied - before the emergence of visible chips from the separated material - by a characteristic noise. This means contact of the blade with the workpiece without chip formation - cutting in the area below the minimum cutting layer thickness.

Analyses of the probable minimum thickness of the machined layer have been the subject of many studies due to the growth of micro-machining with a minimum allowance (so-called thin layers). Only some of the research works are indicated in the list of literature. They refer to research carried out in individual centers in Poland.

Some of these analyzes concern the development of the model based on material and geometric simplification assumptions [2, 3, 6-8]. Other tests refer to conducting experiments and determining the minimum thickness of the cutting layer by contacting direct measurement of the parameter, microhardness analysis and analysis of the contact zones of the tool and the work surface using optical measuring instruments $[1,4,5,9]$. Also, these studies have

\footnotetext{
* Prof. dr hab. inż. Borys Storch (borys.storch@tu.koszalin.pl, prof nadzw. dr hab. inż. Anna Zawada-Tomkiewicz (anna.zawadatomkiewicz@tu.koszalin.pl), dr inż. Łukasz Żurawski (lukasz.zurawski@tu.koszalin.pl),) - Katedra Inżynierii Systemów Technicznych i Informatycznych, Wydział Mechaniczny Politechniki Koszalińskiej
}

many limitations in industrial use. Limitations on the use of theoretical and experimental methods result from the stochastic character of the chip separation phenomenon.

The minimum thickness of the cutting layer depends on the cutting conditions, including the properties of the workpiece as well as the tool material and geometry. For materials with limited chip-forming ability, techniques are used to reduce the probable thickness of the machined layer. One of them is changing the properties of the cut material by changing the cutting temperature and stresses in the workpiece - that is, the thermodynamic conditions of cutting.

For example, when machining titanium and magnesium alloys, cryogenic conditions were used to reduce the minimum thickness of the cutting layer, in other studies the radius of the cutting edge was reduced until the open chip was obtained (fig. 1) and the cutting process was completely abolished.
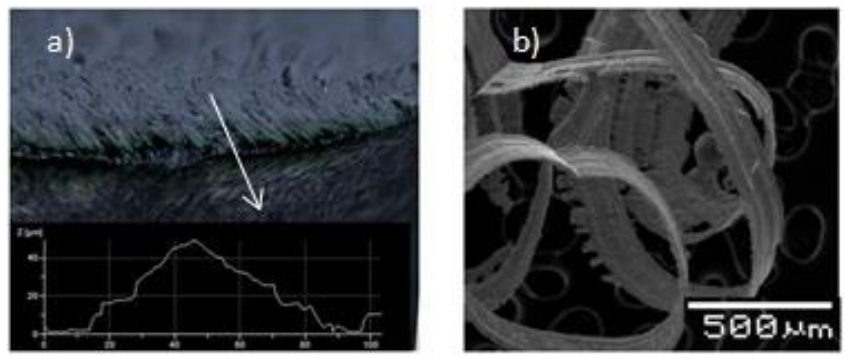

Fig. 1. Cutting edge CD10 (a), openwork chip (free orthogonal cutting with feed $0.001 \mathrm{~mm} / \mathrm{rev}$, cutting speed $150 \mathrm{~m} / \mathrm{min}$ and cutting depth $900 \mu \mathrm{m})(\mathrm{b})$

The purpose of this article is to describe the testing method associated with the determination of the probable minimum thickness of the machined layer.

When chips appear, in relation to the radius of the rounding of the cutting edge $r_{n}$ there is a phenomenon of decohesion in the area constituting a fraction of the radius of the rounding of the cutting edge. Contrary to the model assumptions, the transition from the stresses of the elastic impact of the cutting edge to the volume of the removed chip does not occur in one presumed plane (as many authors believe), but in a given volume of material. This is a serious difficulty in modeling. 
In the model tests, it was found that the limit of strength of the machined material - the beginning of decohesion ahead of the edge by approximately two thicknesses of the machined layer.

\section{Extrapolating force component values to the minimum layer thickness}

A linear relations between the cutting force components $F_{\mathrm{c}}$ and $F_{\mathrm{f}}$ can be observed as a function of the thickness of the cutting layer $h$ in the area delimited by the radius of rounding the cutting edge $r_{\mathrm{n}}$ (fig. 2).

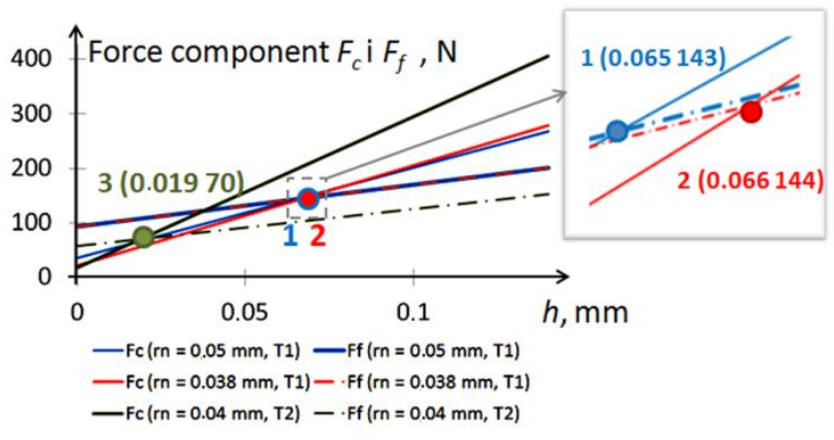

Fig. 2. Extrapolation of the cutting forces to $h=0$ for two different temperatures $T_{1}$ and $T_{2}$ (steel C35, sintered carbides)

Fig. 2 summarizes the expression from the extrapolation based on the components of the cutting force as a function of the thickness of the cut layer $h$. The components for the same cutting conditions and the set temperature are equal in the case of similar values of the thickness of the machined layer (points 1 and 2). If the cutting temperatures are different, the components intersect for the thickness of the cutting layer more distant (point 3).

The results of tests of four cut materials with variable feeds and cutting speeds in conditions described as free and orthogonal were collected. While calculating the abovementioned relations, calculations were carried out in order to run under conditions of a fixed temperature value. The tests were carried out for technological parameters corresponding to most finishing machining conditions, i.e. below the feed $f$ $=h<0.2 \mathrm{~mm}$.

The calculations made on the subsequent stages of experiment for free turning are summarized in fig. 3.

In arbitrarily determined conditions, limited by the possibilities of research, after statistical elaboration, sets of linear equations for variable cutting materials and tools for constant cutting temperatures were determined. The choice of linear equations to extrapolate depending on the thickness of the machined layer resulted from the dimensional analysis. In fig. 3, these are the coordinate systems for the functions $F_{\mathrm{c}}=f(h)$ and $F_{\mathrm{f}}=f(h)$.

In the next step, the increments in force components and $A_{\mathrm{f}} / A_{\mathrm{c}}$ quotients were calculated, which are understood as the unit resistance of the cutting force components [6-7] for the cutting width of $1 \mathrm{~mm}$.

In calculations, the results of which are presented in figs. 4-6, the following assumptions were made:

- measured radius values between $0.016 \div 0.05 \mathrm{~mm}$ were modeled as a function of the ratio $A_{\mathrm{f}} / A_{\mathrm{c}}$ changing from 0 to 1 ,

- temperature measurements were made using a foreign thermocouple for the same cutting tool,

- temperature measurements using a natural thermocouple for a high speed steel knife were carried out in the system,

- width of the cutting layer was fixed on $1 \mathrm{~mm}$,

- paper [8] describes the methodology ensuring repeatability of test results and constancy of the cutting temperature for variable feed values and cutting speed,
- the obtained equations $F_{\mathrm{c}}$ and $F_{\mathrm{f}}$, depending only on $h$ the thickness of the machined layer, are the result of extrapolation in the studied area (from 0 to $r_{\mathrm{n}}$ ).

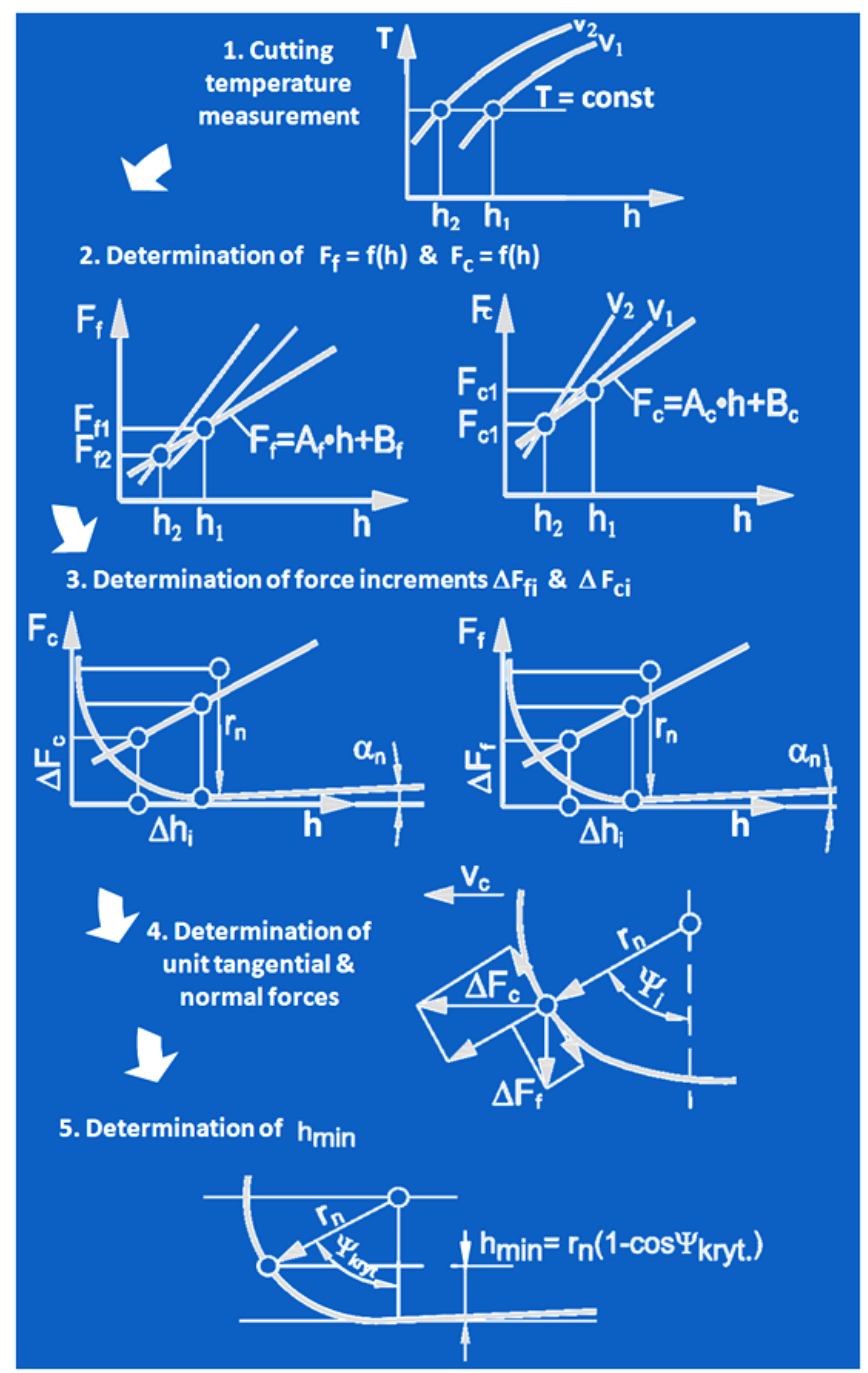

Fig. 3. Algorithm for determination of the minimum thickness of the machined layer, taking into account the components of force and cutting temperature

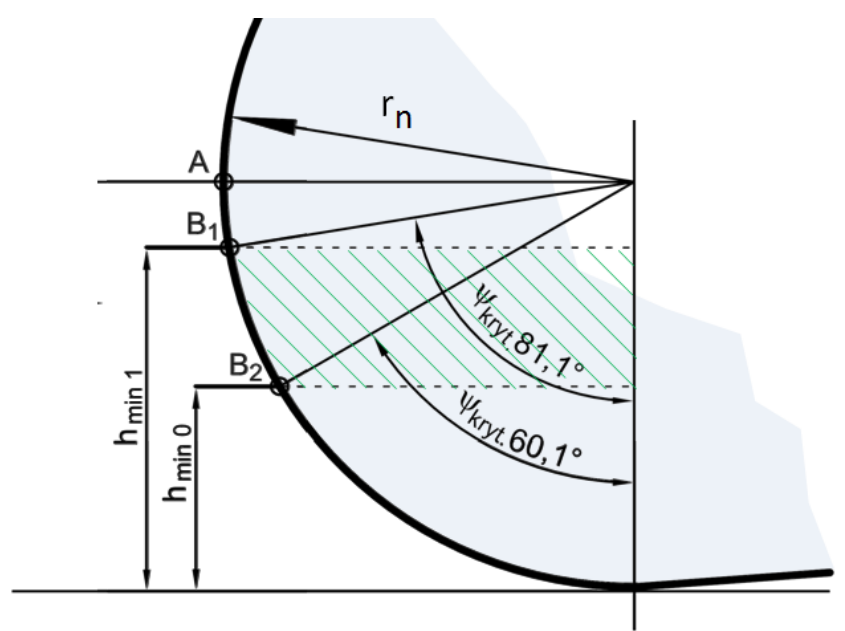

Fig. 4. Free-cutting model with indication of critical values

The introduction of ordered values of the thickness of the machined layer from the range hmin0 to hmin1 and the angles $\psi_{\text {kryt }}$ from the range of 67.50 to 77.50 enables determination of the probable value of the thickness of the machined layer. These thicknesses are conventionally 
marked in the literature as minimal and determined as the difference between the radius $r_{\mathrm{n}}$ and the segments $A_{\mathrm{Bi}}$ :

$$
\begin{aligned}
& \overline{A B}_{i}=\sin \left(90^{\circ}-\psi_{k r y t i}\right) r_{n} \\
& h_{\min }=r_{n}-\overline{A B}_{i}
\end{aligned}
$$

where: $A_{\mathrm{Bi}}$ - variable segments depending on $\boldsymbol{\psi}_{\text {kryt. }}$

For the presented studies, $h_{\min }$ values range from 0.010 to $0.031 \mathrm{~mm}$ and indicate the obtained range between the smallest value $r_{\mathrm{n}}=0.016 \mathrm{~mm}$ and the largest $r_{\mathrm{n}}=0.05 \mathrm{~mm}$ in relation to the largest, in this case measured $0.05 \mathrm{~mm}$. The remaining measured real radiuses of the edge rounding are thus in the range from 0 to 1 .

$$
h_{\min 0}=\frac{0,016}{0,05} \approx 0, h_{\min 1}=\frac{0,05}{0,05}=1
$$

\section{Analysis of results and conclusions}

The tests of determination of the minimum thickness of the machined layer were carried out at the set cutting temperature in each machining case. In work [7], the dependencies of feed and cutting speed were shown - their mutual compensation to obtain the same temperature. The choice of feed and cutting speed allows keeping the set cutting temperature by increasing one and reducing the other of these values. For the linear forces $F_{\mathrm{c}}$ and $F_{\mathrm{f}}$, the coefficients $A_{\mathrm{c}}$ and $A_{\mathrm{f}}$ were determined in the area of the radii of the rounding of the cutting edge bounded by the radius $r_{n}$ according to fig. 2 . The values of the coefficients depend only on the radius of the rounding of the cutting edge $r_{\mathrm{n}}$ and the cutting parameters. The directional coefficients in $F_{\mathrm{c}}=f(h)$ and $F_{\mathrm{f}}=f(h)$ make it possible to determine the critical angle value.

$$
\psi_{\text {kryt }}=\operatorname{arcctg} \frac{A_{f}}{A_{c}}
$$

The desired angular coordinate of the point location at the edge rounding, for which the thickness of the cut layer is equal to the assumed minimum thickness $h_{\min }$, determines the conditions favorable to the creation of the chip.

The quotient for the most machined materials in the equation (4) ranges between zero and one, since the value of $A_{\mathrm{f}}$ is less than $A_{\mathrm{c}}$.

The variability interval of the quotient is illustrated in fig. 5. Additionally, the quotient of the component $F_{\mathrm{f}}$ to the $F_{\mathrm{c}}$ component of the cutting force, determined as the friction coefficient $\mu$, was drawn in the form of the upper and lower range of acceptable analytical values. The bottom curve and the upper curve determine the boundary area of the angle variation for the assumed variance interval of the quotient. The upper curve for the condition $\mu=0$ assumes the occurrence of only the normal force, while the lower one when the tangent and normal forces are equal.

The area highlighted in fig. 5 indicates the range of variability of experimental data. It is a small, limited area associated with the probable value of the minimum thickness of the machined layer. From the tests of various machined materials (different grades of steel, cast iron, aluminum alloys and brass) and tools made of sintered carbide and high speed steel, a range of critical angle values was obtained, which is shown in fig. 6 .

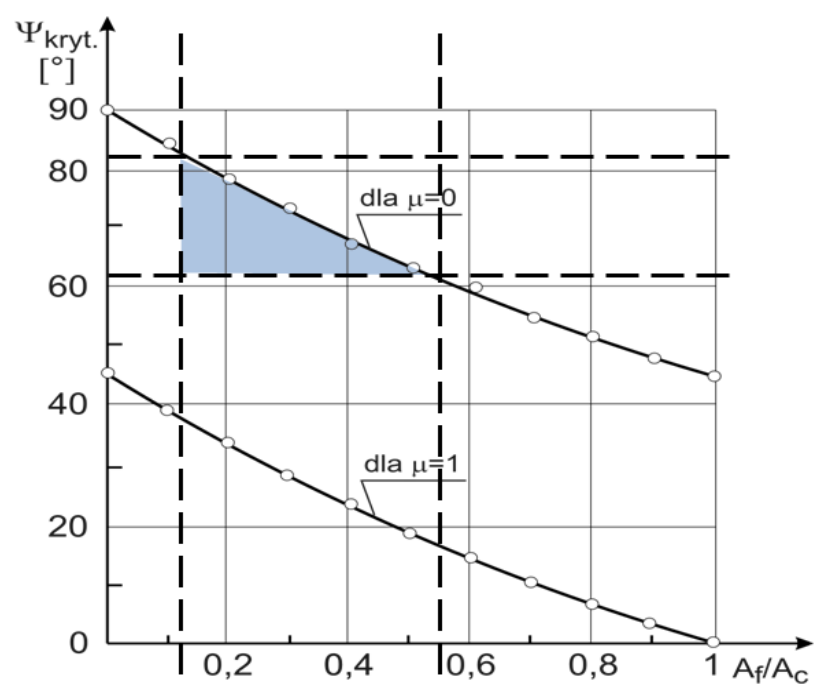

Fig. 5. Influence of the $A_{\mathrm{f}} / A_{\mathrm{c}}$ ratio on changes in the $\psi_{\text {kryt }}$ angle

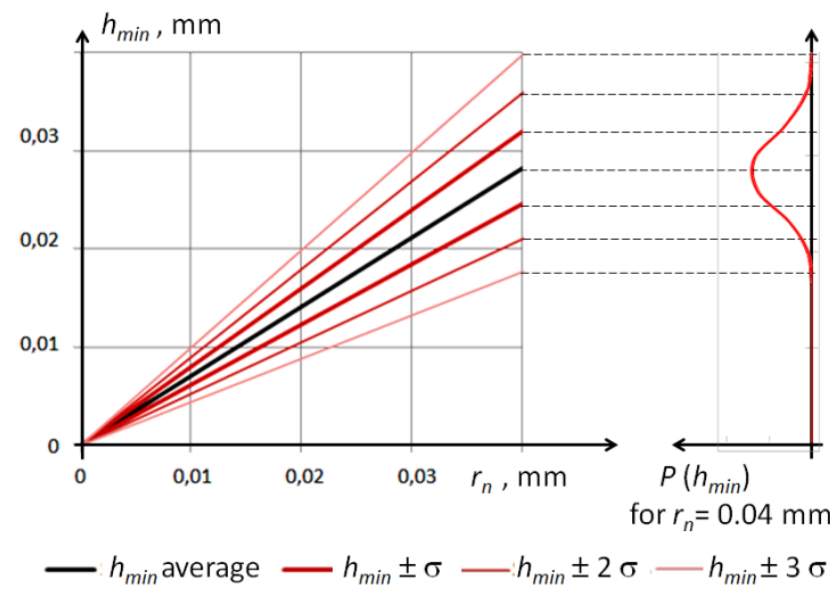

Fig. 6. Dependence of the minimum thickness of the cut layer on the radius of the edge rounding and the probability distribution of the value $h_{\min }$ for $r_{\mathrm{n}}=0.04 \mathrm{~mm}$

The most likely values of the minimum machined layer thickness for the radius of the cutting edge rounding result from the critical angle variability range. Analysis of the distribution probability realized for the previously calculated minimum thickness of the cut layer, depending on the radius of the rounding of the cutting edge for $r_{\mathrm{n}}=0.04 \mathrm{~mm}$, takes into account the actual values of the standard deviation.

After substituting for the equation [7], the formula determining the minimum thickness takes the form:

$$
h_{\min }=r_{n}\left(1-\frac{A_{f} / A_{c}}{\sqrt{1+\left(A_{f} / A_{c}\right)^{2}}}\right)
$$

which, as has been shown, depends on the radius of rounding $r_{\mathrm{n}}$ and the coefficients that can be considered as the components of the cutting resistance in an orthogonal cutting system.

Presented results allow further work related to stress modeling using the FEM method.

\section{REFERENCES}

1. Chwalczuk T., Kawalec M., Szablewski P. „Wybrane właściwości warstwy wierzchniej po toczeniu tradycyjnym i ukośnym ostrzami ceramicznymi nadstopu niklu Inconel 718 po nagrzewaniu laserowym". Mechanik. 7-8 (2012): pp. 409-414. 
2. Grzesik W. „Mechanics of cutting and chip formation”. J. Davim (red.) Machining of Hard Materials. London: Springer, 2011.

3. Harasymowicz J., Gawlik J., Warziniak W. „Sposób określania minimalnej grubości warstwy skrawanej według patentu $P$. 252621". Politechnika Krakowska, 1988.

4. Makieła W., Gogolewski D., Nowakowski Ł. „Wyznaczanie minimalnej grubości warstwy skrawanej z wykorzystaniem dwuwymiarowej transformaty falkowej". Mechanik. 11 (2016): pp. 1632-1633.

5. Nowakowski Ł., Miko E. „Pomiar minimalnej grubości warstwy skrawanej dla procesu frezowania czołowego". Mechanik. 7 (2013): pp. 521-525.

6. Storch B., Zawada-Tomkiewicz A. "Distribution of unit forces on the tool nose rounding in the case of constrained turning". International Journal of Machine Tools \& Manufacture. 57 (2012): pp. 1-9.

7. Storch B., Zawada-Tomkiewicz A. "Distribution of unit forces on the tool edge rounding in the case of finishing turning". Int $J A d v$ Manuf Technol. 60 (2012): pp. 453-461.

8. Storch B., Zawada-Tomkiewicz A., Żurawski Ł. "Termodynamiczne zależności w toczeniu swobodnym". Mechanik. 10 (2016): pp. 1502-1503.

9. Wojciechowski S., Twardowski P., Wieczorowski M. "Surface texture analysis after ball end milling with Darius surface inclination of hardened steel". Metrology and Measurement Systems. 21/1 (2014): pp. 145-156.

Translation of scientific articles, their computer composition and publishing them on the website www.mechanik.media.pl by original articles in Polish is a task financed from the funds of the Ministry of Science and Higher Education designated for dissemination of science.

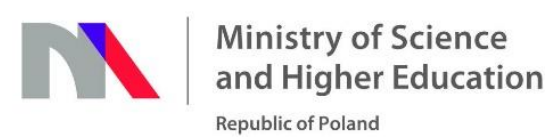

